\title{
Retirement and Healthy Lifestyle: A National Health and Nutrition Examination Survey (NHANES) Data Report
}

\author{
Dana E. King, MD, MS, and Jun Xiang, MS
}

Background: The objective of this study was to compare the rates of healthy lifestyle adherence among retired late-middle-aged adults with rates among those who are still working.

Methods: A national cross-sectional study using data from the National Health and Nutrition Examination survey (NHANES). The main outcome was the proportion of retires versus nonretirees who were adherent to ideal or intermediate goals of the American Heart Association's Life's Simple 7, cardiovascular factors including physical activity, healthy diet, healthy weight, smoking status, total cholesterol, glucose, and blood pressure.

Results: Retirees were more likely than nonretirees to have poorly controlled blood pressure (23.9\% vs $15.1 \% ; P=.05)$. However, there were no differences in healthy weight, smoking rates, healthy diet, or glucose or cholesterol control $(P>.05)$. In controlled logistic regression analyses, retirees were more likely to be physically active than nonretirees (odds ratio, 1.85 ; $95 \%$ confidence interval, $1.11-$ 3.09), but were not more likely to be following any other Life's Simple 7 factors.

Conclusions: Retired adults were more likely to be physically active but were not more likely to be adhering to most of the Life's Simple 7 lifestyle and cardiovascular risk factors. More public health attention to encouraging healthy lifestyles during the transition into retirement may be warranted. (J Am Board Fam Med 2017;30:213-219.)

Keywords: Cardiovascular Diseases, Cross-Sectional Studies, Exercise, Lifestyle, Logistic Regression, Public Health, Retirement, Risk Factors

Recent research demonstrates challenges to healthy lifestyle adherence among late-middleaged adults. ${ }^{1-4}$ Chronic disease, use of multiple medications, and busy daily lives make following a healthy lifestyle more difficult. ${ }^{5}$ Previous studies of

This article was externally peer reviewed.

Submitted 1 August 2016; revised 14 November 2016; accepted 17 November 2016.

From the Department of Family Medicine, West Virginia University School of Medicine, Morgantown.

Funding: The research reported in this publication was supported by the NIGMS of the National Institutes of Health under award U54GM104942.

Prior presentation: This work was presented at the 44th North American Primary Care Research Group Annual Meeting in Colorado Springs, Colorado (November 12-16, 2016)

Conflict of interest: none declared.

Disclaimer: The content is solely the responsibility of the authors and does not necessarily represent the official views of the National Institutes of Health.

Corresponding author: Dana E. King, MD, MS, Robert C. Byrd Health Sciences Center, Morgantown, WV 265069152 (E-mail: kingdana@wvumedicine.org). recent retirees indicate that the transition to retirement may offer an opportunity for a "new start" toward healthy living and greater adherence to recommended patterns of exercise and healthy habits. ${ }^{6}$ More unstructured time in retirement, fewer daily obligations, and relief from daily commuting responsibilities were some of the reasons cited by retirees that might offer increased opportunities to more closely adhere to a healthy lifestyle.

The purpose of this study was to examine whether retired late-middle-aged adults have differing rates of adherence to healthy lifestyle and metabolic risk factors, including diet, exercise, smoking, weight, glucose, blood pressure, and cholesterol, compared with same-aged adults who are not yet retired. ${ }^{7}$ The Life's Simple 7 are part of the American Heart Association's (AHA's) goals for cardiovascular health for 2020. The study population was a national sample of noninstitutionalized adults from the National He- 
alth and Nutrition and Examination Survey (NHANES; 2009 to 2012).

\section{Methods}

\section{Study Population}

The NHANES is a series of complex and multistage surveys aiming to assess the health and nutritional status of the noninstitutionalized population of the United States. The study focused on a subset of the "baby boomer" population, ages 55 to 70 years, a particular population of interest in previous studies. ${ }^{1,3}$ The population was chosen because of the desire to examine recent retirees lifestyles in relation to nonretirees. This study compared the difference in rates of adherence to healthy lifestyle recommendations between late-middle-aged retirees and a similar population who were not retired from the NHANES 2009 to 2010 and NHANES 2011 to 2012 surveys. ${ }^{8}$ This study was reviewed and exempted by the West Virginia University Health Sciences Institutional Review Board.

Two questions were used as the inclusion criteria for the study sample. Respondents who responded "retired" for the question, "What is the main reason you did not work last week?" were chosen as "retirees"; those who chose the answers of either "working at a job or business" or "with a job or business but not at work" to the item "type of work done last week" were extracted as nonretired subjects. Disabled persons were excluded from the study to avoid the results being biased by an inability to exercise or adhere to a healthy lifestyle. Participants who did not answer the designated retirement questions also were excluded from the study.

\section{Healthy Lifestyle Metrics}

Definitions used to measure the 7 components of the study were adherent to Life's Simple 7, a relatively new cardiovascular health index published by the AHA. ${ }^{7}$ The healthy lifestyle metrics selected are physical activity, healthy diet, healthy weight, and smoking status. Three metabolic risk factors also are included in the AHA metrics: total cholesterol, glucose, and blood pressure. These measures were compared between the retired and nonretired groups. Previous studies have examined these same factors in similarly aged populations for the purpose of evaluating cardiovascular risk factors and lifestyle goals. ${ }^{2,3,5,9,10}$
Each component of Life's Simple 7 was classified into 3 categories-ideal, intermediate, and poor-and given a point score of 0,1 , or 2 , respectively. The detailed definitions of the Life's Simple 7 components are presented in Table 1 . We adapted the definitions of the Life's Simple 7 components based on the availability of the NHANES data. For the 3 metabolic risk factor components, we used the current level attained, regardless of treatment, for the measurements and categorized participants according to the AHA's metrics of ideal, intermediate, or poor categories.

For the healthy diet determination, we incorporated the Food Patterns Equivalents Database created by the US Department of Agriculture to the selected NHANES cycles. Instead of using information on sugar-sweetened beverage intake, which was unavailable in the 2 NHANES cohorts we selected, we replaced it with added-sugar intake based on the daily intake recommendation from the AHA. Daily intakes for fruits and vegetables, whole grains, sodium, and added sugar, and number of times per week for all kinds of fish were added together, first from individual food. We then recalculated each individual's fruit and vegetable intake and whole-grain intake based on a recommended 2000 calories/day reference diet. We assigned 1 point each to subjects consuming fruits and vegetables ( $\geq 4.5$ cups/day), whole grains ( $\geq 3$ oz/day), sodium $(<1500 \mathrm{mg} /$ day $)$, added sugar $(<37.5 \mathrm{~g} /$ day for men, $<25 \mathrm{~g} /$ day for women), and fish ( $\geq 2$ times/week). Finally, the points were summed and subjects were categorized in the healthy diet component as " 4 to 5 points" for ideal, " 2 to 3 points" for intermediate, and " 0 to 1 points" for poor.

For physical activity, we calculated the total minutes a subject spent on vigorous and moderate recreational activities per week, then assigned the subjects into categories of ideal, intermediate, and poor according to the definitions in Life's Simple 7.

Other demographic covariates selected for this study included age, sex, height, weight, race, health insurance status, and socioeconomic status (ratio of family income to poverty). Race was combined to 4 categories of "white," "black," "Hispanic," and "other race." Ratio of family income to poverty was recoded as "high" for $\geq 1.0$ and "low" for $<1.0$. Subjects' age, height, and weight were obtained. Health insurance status was divided into 3 categories: no health insurance, public health insurance, and private insurance. Body mass index (BMI) was 
Table 1. American Heart Association (AHA) Definition of Cardiovascular Health Metric (Life's Simple 7)

\begin{tabular}{|c|c|c|}
\hline Health Factors & Levels & AHA Definition* \\
\hline \multirow[t]{3}{*}{ Blood pressure } & Ideal & $<120 /<80 \mathrm{mmHg}$, without treatment \\
\hline & Intermediate & SBP $120-139$ or DBP $80-89 \mathrm{mmHg}$, or treated to $<120 /<80 \mathrm{mmHg}$ \\
\hline & Poor & $\mathrm{SBP} \geq 140 \mathrm{mmHg}$ or $\mathrm{DBP} \geq 90 \mathrm{mmHg}$ \\
\hline \multirow[t]{3}{*}{ Fasting serum glucose } & Ideal & $<100 \mathrm{mg} / \mathrm{dL}$, without treatment \\
\hline & Intermediate & $100-125 \mathrm{mg} / \mathrm{dL}$, or treated to $<100 \mathrm{mg} / \mathrm{dL}$ \\
\hline & Poor & $\geq 126 \mathrm{mg} / \mathrm{dL}$ \\
\hline \multirow[t]{3}{*}{ Total cholesterol } & Ideal & $<200 \mathrm{mg} / \mathrm{dL}$, without treatment \\
\hline & Intermediate & $200-239 \mathrm{mg} / \mathrm{dL}$, treated to $<200 \mathrm{mg} \mathrm{dL}$ \\
\hline & Poor & $\geq 240 \mathrm{mg} / \mathrm{dL}$ \\
\hline \multicolumn{3}{|l|}{ Behavioral factors } \\
\hline \multirow[t]{3}{*}{ Smoking } & Ideal & Never or quit $>12$ months earlier \\
\hline & Intermediate & Former (quit $\leq 12$ months earlier) \\
\hline & Poor & Current \\
\hline \multirow[t]{3}{*}{ Physical activity } & Ideal & $\begin{array}{l}\geq 150 \mathrm{~min} / \text { week moderate, or } \geq 75 \mathrm{~min} / \text { week vigorous, or } \geq 150 \mathrm{~min} / \text { week } \\
\text { moderate + vigorous }\end{array}$ \\
\hline & Intermediate & $\begin{array}{l}1-149 \mathrm{~min} / \text { week moderate, or } 1-74 \mathrm{~min} / \text { week vigorous, or } 1-149 \mathrm{~min} / \mathrm{week} \\
\text { moderate + vigorous }\end{array}$ \\
\hline & Poor & None \\
\hline \multirow[t]{3}{*}{ Healthy weight } & Ideal & $\mathrm{BMI}<25 \mathrm{~kg} / \mathrm{m}^{2}$ \\
\hline & Intermediate & BMI $25-29.9 \mathrm{~kg} / \mathrm{m}^{2}$ \\
\hline & Poor & $\mathrm{BMI} \geq 30 \mathrm{~kg} / \mathrm{m}^{2}$ \\
\hline \multirow[t]{3}{*}{ Healthy diet* } & Ideal & 4 or 5 components \\
\hline & Intermediate & 2 or 3 components \\
\hline & Poor & 0 or 1 component \\
\hline
\end{tabular}

*American Heart Association's (AHA's) healthy diet category contains 5 components: consumption of fruits and vegetables ( $\geq 4.5$ cups/day), fiber-rich whole grain ( $\geq 31$-oz servings/day), sodium ( $<1500 \mathrm{mg} /$ day), sugar-sweetened beverages ( $\leq 36 \mathrm{oz} /$ week), and fish ( $\geq 23.5$-oz servings/week). Our modified healthy diet category also consists of 5 components: consumption of fruits and vegetables ( $\geq 4.5$ cups/day), fiber-rich whole grain ( $\geq 3 \mathrm{oz} /$ day), sodium $(<2300 \mathrm{mg} /$ day), added sugar ( $<37.5 \mathrm{~g} /$ day for men, $<25 \mathrm{~g} /$ day for women), and fish ( $\geq 2$ times/week).

BMI, body mass index; DBP, diastolic blood pressure; SBP, systolic blood pressure.

classified as underweight $\left(<18.5 \mathrm{~kg} / \mathrm{m}^{2}\right)$, normal $(\geq 18.5$ and $\left.\leq 24.9 \mathrm{~kg} / \mathrm{m}^{2}\right)$, overweight ( $\geq 25$ and $\leq 29.9 \mathrm{~kg} / \mathrm{m}^{2}$ ), and obese $\left(\geq 30 \mathrm{~kg} / \mathrm{m}^{2}\right)$ based on the Centers for Disease Control and Prevention breakdown.

\section{Statistical Analysis}

SAS software (version 9.3; SAS Institute Inc., Cary, $\mathrm{NC)}$ was used to perform the statistical analysis. We incorporated the 4-year weights calculated using the method provided by NCHS (National Center for Health Statistics) to account for the complex survey design (including oversampling), survey nonresponse, and poststratification. The presence of a difference between retirees and nonretirees was determined using a $\chi^{2}$ analysis with the SURVEYFREQ procedure and regression analysis with the SURVEYREG procedure. For some of the analyses, the sample size was affected by the somewhat smaller subsample of individuals who had glucose testing measurements available in the NHANES 2009 to 2012 cohorts.
To further analyze the data, we constructed a new dichotomous variable for each of the 7 components of the study. Except healthy diet, all other 6 components were recoded using " 1 " for ideal category and " 0 " for the other categories. We recoded healthy diet combining ideal and intermediate as " 1 " and poor as " 0 " because of the very small number of respondents in the "ideal" category. A logistic regression analysis using the SURVEYLOGISTIC procedure was then conducted to see whether the results were consistent with the $\chi^{2}$ analysis when adjusted for age, sex, race, health insurance status, and socioeconomic status. $P<.05$ was used to account for statistical significance.

\section{Results}

The description and demographics of the study sample are illustrated in Table 2. The sample of 956 individuals, 475 from NHANES 2009 to 2010 
Table 2. Unweighted Sociodemographic Characteristics of Subjects from the National Health and Nutrition Examination Survey, 2009-2012

\begin{tabular}{|c|c|c|c|}
\hline Characteristic & Retirees $(\mathrm{n}=359)^{*}$ & Nonretirees $(\mathrm{n}=597)^{*}$ & $P$ Value $^{\dagger}$ \\
\hline Age, years $($ mean $\pm \mathrm{SD})$ & $65.6 \pm 3.5$ & $61.0 \pm 4.3$ & $<.0001$ \\
\hline \multicolumn{4}{|l|}{ Sex } \\
\hline Male & 52.4 & 57.1 & \multirow[t]{2}{*}{.04} \\
\hline Female & 47.6 & 42.9 & \\
\hline Height, cm (mean $\pm \mathrm{SD})$ & $166.9 \pm 9.5$ & $168.2 \pm 10.1$ & .0003 \\
\hline Weight, $\mathrm{kg}($ mean $\pm \mathrm{SD})$ & $84.3 \pm 20.6$ & $82.2 \pm 19.4$ & .25 \\
\hline \multicolumn{4}{|l|}{ Race } \\
\hline Hispanic & 21.2 & 26.3 & \multirow[t]{4}{*}{.58} \\
\hline White & 41.8 & 41.0 & \\
\hline Black & 27.9 & 21.3 & \\
\hline Other & 9.2 & 11.4 & \\
\hline \multicolumn{4}{|l|}{ Body mass index } \\
\hline Underweight $\left(<18.5 \mathrm{~kg} / \mathrm{m}^{2}\right)$ & 0.9 & 0.7 & \multirow[t]{4}{*}{.62} \\
\hline Normal weight $\left(\geq 18.5\right.$ but $\left.\leq 24.9 \mathrm{~kg} / \mathrm{m}^{2}\right)$ & 20.5 & 26.0 & \\
\hline Overweight $\left(\geq 25\right.$ but $\left.\leq 29.9 \mathrm{~kg} / \mathrm{m}^{2}\right)$ & 32.1 & 35.5 & \\
\hline Obese $\left(\geq 30 \mathrm{~kg} / \mathrm{m}^{2}\right)$ & 46.5 & 37.8 & \\
\hline \multicolumn{4}{|l|}{ Health insurance } \\
\hline None & 7.0 & 18.8 & \multirow[t]{3}{*}{$<.0001$} \\
\hline Private & 55.0 & 66.8 & \\
\hline Public & 38.0 & 14.4 & \\
\hline \multicolumn{4}{|l|}{ Ratio of family income to poverty } \\
\hline$\geq 1.0$ & 86.2 & 88.7 & \multirow[t]{2}{*}{.24} \\
\hline$<1.0$ & 13.8 & 11.3 & \\
\hline
\end{tabular}

Data are percentages unless otherwise indicated.

*Numbers of subjects in each category may be different because of the missing values for some variables.

${ }^{\dagger} P$ value from the $\chi^{2}$ test (categorical variables) and regression analysis (continuous variables) comparing the difference in demographic variables between late retirees and nonretirees.

$\mathrm{SD}$, standard deviation.

and 481 from NHANES 2011 to 2012, represents a population estimate of $19,724,643$ people.

The results presented in Table 3 indicate that retired late-middle-aged adults were more likely to have poorly controlled blood pressure $(23.9 \%$ vs $15.1 \% ; P=.05)$ than nonretirees. They were not more likely than their counterparts to have low physical activity (44.6\% vs $47.8 \% ; P=.17$ ), achieve an ideal or intermediate healthy weight $(52.4 \%$ vs $60.0 \% ; P=.25$ ), or have an ideal or intermediate healthy diet $(29.9 \%$ vs $22.6 \% ; P=.21)$. Nonsmoking rates were similar among retirees and nonretirees $(86.5 \%$ vs $83.7 \% ; P=.27)$. There were no differences in glucose or cholesterol control $(P>.05)$.

In logistic regression analyses presented in $\mathrm{Ta}-$ ble 4 , after adjusting for age, sex, race, health insurance status, and socioeconomic status, retirees were more likely to be physically active than nonretirees (OR, 1.85; 95\% CI, 1.11-3.09), but not more likely to be following a healthy diet or controlling blood pressure, weight, or any of the other Life's Simple 7 factors.

\section{Discussion}

This study demonstrates that retired adults generally were no more likely to be adherent to the AHA's Life's Simple 7 healthy lifestyle recommendations in several important measures compared with same age nonretired individuals. After controlling for socioeconomic and demographic factors, only physical activity was more likely to be greater in retirees. Retirees' adherence to ideal or intermediate goals for smoking, cholesterol, BMI, glucose, and diet were not significantly different from nonretired adults of similar age.

These results indicate that taking advantage of added time to attend to a healthier lifestyle during retirement is not occurring on a regular basis. The 
Table 3. Comparison of the Prevalence of the 7 Components of the Life's Simple 7 Between Retirees and Nonretirees

\begin{tabular}{|c|c|c|c|c|c|}
\hline \multirow[b]{2}{*}{ Cardiovascular Health Metric } & \multicolumn{2}{|c|}{ Retirees } & \multicolumn{2}{|c|}{ Nonretirees } & \multirow[b]{2}{*}{$P$ Value } \\
\hline & No. & Prevalence & No. & Prevalence & \\
\hline Smoking status & & & & & .27 \\
\hline Ideal & 297 & 86.5 & 491 & 83.7 & \\
\hline Intermediate & 10 & 2.3 & 11 & 1.0 & \\
\hline Poor & 52 & 11.2 & 94 & 15.2 & \\
\hline Healthy weight & & & & & .25 \\
\hline Ideal & 67 & 18.3 & 149 & 24.6 & \\
\hline Intermediate & 114 & 34.1 & 210 & 35.4 & \\
\hline Poor & 174 & 47.6 & 233 & 40.0 & \\
\hline Physical activity & & & & & .17 \\
\hline Ideal & 128 & 41.9 & 165 & 33.5 & \\
\hline Intermediate & 50 & 13.4 & 98 & 18.7 & \\
\hline Poor & 181 & 44.6 & 334 & 47.8 & \\
\hline Total cholesterol & & & & & .81 \\
\hline Ideal & 195 & 52.6 & 305 & 49.6 & \\
\hline Intermediate & 114 & 35.0 & 204 & 35.5 & \\
\hline Poor & 44 & 12.3 & 82 & 14.9 & \\
\hline Blood pressure & & & & & .05 \\
\hline Ideal & 101 & 31.1 & 188 & 39.4 & \\
\hline Intermediate & 158 & 45.0 & 258 & 45.5 & \\
\hline Poor & 88 & 23.9 & 126 & 15.1 & \\
\hline Glucose & & & & & .07 \\
\hline Ideal & 90 & 29.9 & 225 & 40.7 & \\
\hline Intermediate & 168 & 53.1 & 257 & 46.2 & \\
\hline Poor & 76 & 17.0 & 89 & 13.1 & \\
\hline Healthy diet & & & & & .21 \\
\hline Ideal & 7 & 1.4 & 7 & 1.5 & \\
\hline Intermediate & 91 & 28.5 & 139 & 21.1 & \\
\hline Poor & 240 & 70.2 & 418 & 77.4 & \\
\hline
\end{tabular}

${ }^{*} P$ value from $\chi^{2}$ test comparing the difference of prevalence among the 7 components of the Life's Simple 7 between late-middle-age retirees and nonretirees.

reasons are not entirely clear, but several possibilities could be considered.

New retirees may not have retired voluntarily, and instead may have become disabled by illness or injury that made them unable to continue working. ${ }^{11-13}$ This study excluded disabled persons to reduce the risk of this bias.

Another possibility is that limited financial or other social resources may change during retirement and make it more difficult for new retirees to consume a healthy diet and or other lifestyle activities. $^{14,15}$ Fresh foods, medication costs and copays, and other healthy lifestyle costs may not be in the limited budget of many retirees. In this study, even after controlling for demographic, insurance, and socioeconomic status, the retirees did not sig-
Table 4. Logistic Regression Estimates for Comparing the Prevalence of the 7 Components of the Life's Simple 7 Between Retirees and Nonretirees, Controlling for Demographic Variables

\begin{tabular}{lcc}
\hline $\begin{array}{l}\text { Cardiovascular Health } \\
\text { Metric }\end{array}$ & Odds Ratio* & $\begin{array}{c}\text { 95\% Confidence } \\
\text { Interval }\end{array}$ \\
\hline Smoking status & 1.05 & 0.51 to -2.17 \\
Healthy weight & 1.53 & $0.89-2.64$ \\
Physical activity & 1.85 & $1.10-3.09$ \\
Total cholesterol & 1.05 & $0.52-2.11$ \\
Blood pressure & 0.66 & $0.38-1.14$ \\
Glucose & 0.68 & $0.39-1.18$ \\
Healthy diet & 1.37 & $0.78-2.43$ \\
\hline
\end{tabular}

*Odds ratios for Life's Simple 7 item prevalence after adjusting for age, sex, race, health insurance status, and poverty level. 
nificantly increase most healthy lifestyle habits, with the exception of physical activity. This exception may be because of the relative ease of walking and other similar physical activities (gardening, bicycling) that present few barriers or expense to retirees.

Another possibility to explain mostly no change in healthy lifestyle factors is that the reduced social interaction during retirement and isolation from the workplace may affect mood or motivation to pursue a healthy lifestyle. ${ }^{16,17}$ Such isolation could diminish opportunities for reinforcement of healthy lifestyles or motivation for healthy living. In addition, transportation options may change during retirement, such that trips to fresh food markets or medical appointments may be less available. In this study we were able to take age, sex, race, and socioeconomic status into account, but we did not have access to specific social isolation parameters that might also mediate the association.

The study also has several strengths worth reviewing. The study was conducted using a national sample of noninstitutionalized adults that is weighted for demographic factors that might skew the sample. ${ }^{8}$ In addition, the study included confirmation of clinical parameters not found in many national surveys, including blood pressure, cholesterol, and glucose levels. ${ }^{2,3,9,10}$

This study also has some limitations. The sample is cross-sectional; thus the data can be used to explore associations but not support causality. In addition, the information is directly from the participants' self-report, without other confirmation of diagnoses or adherence to lifestyle habits. Finally, the transition to retirement is multifaceted; thus survey questions regarding retirement status are inherently 1-dimensional assessments of a complex situation. $^{18}$

\section{Conclusion}

The findings of this study indicate that retirement does not have a strong association with improvements in healthy lifestyle habits or other cardiovascular risk factors. Retired baby boomers were no more likely to be controlling their weight, blood Pressure, or glucose, and were no more likely to be following a healthy diet. Only physical activity was likely to increase after retirement. Research is needed to further understand health and lifestyle challenges during the transition to retirement.
To see this article online, please go to: http://jabfm.org/content/ 30/2/213.full.

\section{References}

1. King DE, Xiang J, Brown A. Intake of key chronic disease-related nutrients among baby boomers. South Med J 2014;107:342-7.

2. Alter DA, Wijeysundera HC, Franklin B, et al. Obesity, lifestyle risk-factors, and health service outcomes among healthy middle-aged adults in Canada. BMC Health Serv Res 2012;12:238.

3. King DE, Matheson E, Chirina S, Shankar A, Broman-Fulks J. The status of baby boomers' health in the United States: the healthiest generation? JAMA Intern Med 2013;173:385-6.

4. King DE, Mainous AG 3rd, Lambourne CA. Trends in dietary fiber intake in the United States, 19992008. J Acad Nutr Diet 2012;112:642-8.

5. King DE, Mainous AG 3rd, Carnemolla M, Everett CJ. Adherence to healthy lifestyle habits in US adults, 1988-2006. Am J Med 2009;122:528-34.

6. McDonald S, O'Brien N, White M, Sniehotta FF. Changes in retirement during the retirement transition: a theory-based, qualitative interview study. Int J Behav Nutr Phys Act 2015;12:25.

7. American Heart Association. Life's Simple 7. Available from https://www.heart.org/idc/groups/heartpublic/@wcm/@swa/documents/downloadable/ ucm_425189.pdf. Accessed July 20, 2016.

8. Center for Disease Control and Prevention, National Center for Health Statistics. National Health and $\mathrm{Nu}-$ trition Examination Survey. Available from http:// www.cdc.gov/nchs/nhanes/about_nhanes.htm. Updated February 3, 2014. Accessed May 19, 2016.

9. Kulshreshtha A, Vaccarino V, Goyal A, et al. Family history of stroke and cardiovascular health in a national cohort. J Stroke Cerebrovasc Dis 2015;24: $447-54$.

10. Kulshreshtha A, Vaccarino V, Judd SE, et al. Life's Simple 7 and risk of incident stroke: the reasons for geographic and racial differences in stroke study. Stroke 2013;44:1909-14.

11. Kalyani RR, Rodriguez DC, Yeh HC, Golden SH, Thorpe RJ Jr. Diabetes, race, and functional limitations in older U.S. men and women. Diabetes Res Clin Pract 2015;108:390-7.

12. Saltman AP, Silver FL, Fang J, Stamplecoski M, Kapral MK. Care and outcomes of patients with in-hospital stroke. JAMA Neurol 2015;72:749-55.

13. McClurkin MA, Yingling LR, Ayers C, et al. Health insurance status as a barrier to ideal cardiovascular health for U.S. adults: data from the National Health and Nutrition Examination Survey (NHANES). PLoS One 2015;10:e0141534.

14. Puckrein GA, Egan BM, Howard G. Social and medical determinants of cardiometabolic health: the big picture. Ethn Dis 2015;25:521-4. 
15. Nandi A, Glymour MM, Subrumanian SV. Association among socioeconomic status, health behaviors and all-cause mortality in the United States. Epidemiology 2014;25:170-7.

16. Rudolph KE, Eaton WW. Previous anxiety and depression as risk factors for early labour force exit. J Epidemiol Community Health 2016;70: $390-5$.
17. Gerst-Emerson K, Jayawardhana J. Loneliness as a public health issue: the impact of loneliness on health care utilization among older adults. Am J Public Health 2015;105:1013-9.

18. Kim JE, Moen P. Retirement transitions, gender, and psychological well-being: a life-course, ecological model. J Geronotol B Psychol Soc Sci 2002;57: P212-22. 